\title{
Microscopic approach for the evaluation of an urban transport system in emergency conditions
}

\author{
G. Musolino \& A. Vitetta \\ Department of Computer Science, Mathematics, Electronics and \\ Transportation, Mediterranea University of Reggio Calabria, Italy.
}

\begin{abstract}
The paper presents some traffic microscopic models and procedures for the analysis and management of a road transportation system, when an evacuation of a densely populated area has to be planned, due to a forthcoming calamitous event.

In the sphere of Dynamic Traffic Assignment (DTA), the microscopic approach allows a disaggregate analysis of each driver behaviour in terms of speed and acceleration and the simulation of queuing and lane-changing phenomena; but it needs high computation times for extended transportation networks analysis and large amount of data for the behavioural rules definition.
\end{abstract}

\section{Introduction}

The aim of this work is the analysis and the management of a road transportation system by means of traffic microscopic models and procedures, when the population evacuation of a urban area is necessary, because of the approximation of a calamitous event.

In such context, where temporary sovra-saturation phenomena of some transportation supply elements, queues formation and dispersion are present, methods and procedures for Dynamic Traffic Assignment (DTA) become necessary, which can have different models or specifications: pseudo dynamic [1], mesoscopic [2] or microscopic, presented in this paper.

Microsimulation procedures require the use of microscopic traffic flow models, path choice and assignment models. Microscopic traffic flow models belong to 


\section{Environmental Health Risk}

two different classes:

- link models, that simulate the interactions among vehicles on each link of the network;

- node models, that simulate the interactions among vehicles on each node of the network (signlized and not-signalized intersections, merging and diverging areas, toll plaza areas, ....).

Link models can be divided in two categories: car-following models, that simulate the movement of each vehicle and the interaction with vehicles travelling dowstream on the same lane; lane-changing models, that simulate the interactions among vehicles travelling on different lanes.

Car-following models can be subdivided in two classes:

- monoregime models, based on the "stimulus-reaction" concept ([3], [4], [5], $[6],[7],[8],[9],[11][12],[13])$, that describe vehicles interactions in the different flow regimes by means of one equation;

- multiregime models, based on the "stimulus-reaction" ([14], [15]) and "safety speed" concepts [16], that describe vehicles interactions in the different flow regimes by means of multiple equations.

Lane-changing models, depending of the manoeuvre to be simulated, can be classified as follows:

- mandatory ([17], [18], [19], [20], [21], [22]), when the driver must necessarily execute the lane-changing manoeuvre in order to reach the destination lane (es. merging manoeuvre, lane number reduction, etc.);

- discretionary ([19], [18], [23], [20]), when the driver performs the lanechanging manoeuvre in order to reach his desired speed.

Moreover, lane-changing models can be distinguished in: urban and extraurban; deterministic or stochastic, according to the nature of the variables.

Among node models, there are models for signalized nodes and models for notsignlized nodes.

Models for signalized nodes can be subdivided in: macrocospic, for an aggregate analysis of node performances [24] and microscopic, for a disaggregate analysis of node performances, simulating explicitly every driver behaviour. In the microsimulation procedures a virtual vehicle is located on the final section of the entering link during the red phase of the traffic light; the virtual vehicle is removed at the beginning of the green phase, reproducing the traffic light cycle ([25], [26], [19]).

Models for not-signalized nodes are based on the gap-acceptance model. Different gap-acceptance models have been developed ([27], [28], [29], [30], [20], [31]) according to the assumptions of the critical gap distribution. Federal HighWay Administration [20] proposed a methodology based on average critical gap for the estimation of delay and capacity at the intersection.

References of microscopic traffic flow models proposed in literature are presented in figure 1 , according to the previous classification. 


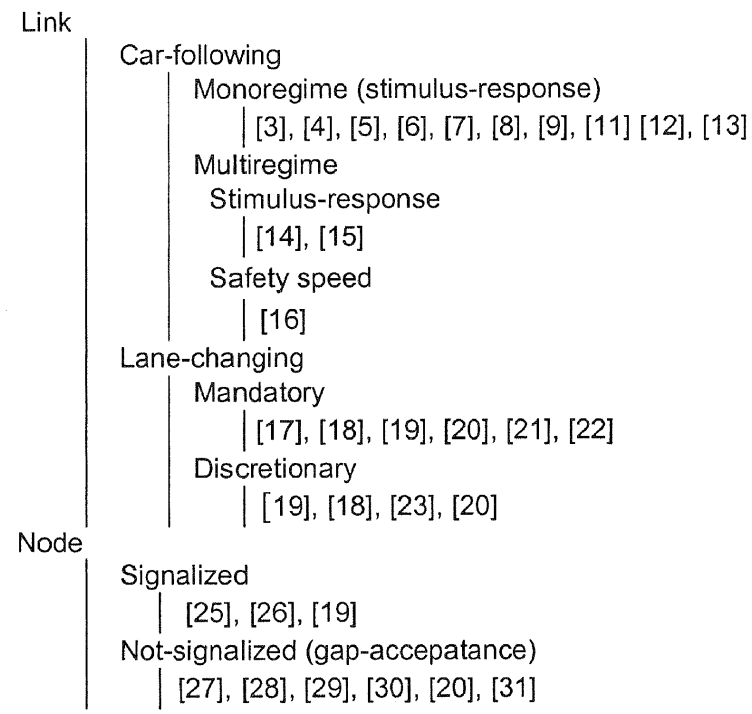

Figure 1: Classification of microscopic traffic flow models.

The specification of path choice models requires the definition of the path choice set and the path choice models. The path choice set is generally defined in a behavioural way, in other words, selecting admissible paths according to behavioural rules of the driver. Paths inside the path chice set can be variable or fixed, if new paths can be periodically reconsidered from the drivers or not.

Path choice models [32], on variable or fixed path choice set, can be:

- pre-trip, when the driver chooses the path according to the origin, the destination and departure time, before starting the trip;

- en-route, when the driver modifies, during the trip, the path on the base of current traffic conditions on the network.

Among the path choice models, we can distinguish two types of models:

- deterministic, if the driver chooses the path with the minimum cost;

- stocahstic, if the driver associates a probability to each path belonging to the path choice set.

The en-route choice implies that information concerning current traffic conditions on the network are available. Modeling driver reaction to the available information is part of ATMS/ATIS systems, not treated in this work.

Figure 2 shows a picture of path choice models, as previous classified.

The assignment model ([33], [34], [32]) provides path flows concerning drivers which departe from an origin, o, in a temporal interval, to reach the destination, d. Path flows depend on the demand flows from the origin, o, to the destination, $\mathrm{d}$, which depart in the considered interval, and from the path choice probability, given the departure time and the o/d couple. From the path flows it is possible to obtain link flows for every time interval. 
240 Environmental Health Risk

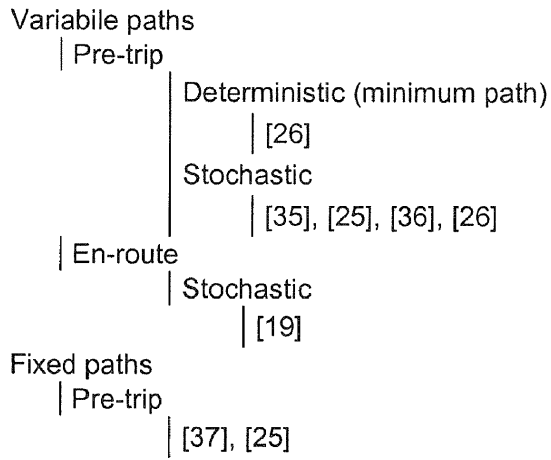

Figure 2: Classification of path choice models.

Few literature concerning the analysis of a transportation system in emergency conditions is present. In [38], it is faced the definition of path choice sets for pedestrian evacuation in pubblic buildings, by means of a dynamic network loading model of demand flows on the network; in [39], evacuation times by means of a mesoscopic approach in the Vesuvio volcano area (Italy) are estimated; [40] and [1] present a pseudo dynamic approach for the demand management at departure time and distribution dimensions for the evacuation of population from an urban area; in [41] and [42], general models and procedures to be used in a "what if" and "what to" approach of road transportation network analisys in emergency conditions are described and classified.

The paper presentes microscopic models and procedures for the analysis and management of a road trasportation system in emergency conditions, when the transportation network is loaded by high and concentrated demand.

The paper is articulated in four sections. In section 2 some definitions and notations are introduced and the traffic microscopic model used is presented. Section 3 describes the microsimulation procedures. In section 4 the conclusions and the research perspectives are highlighted.

\section{Models}

\subsection{Definitions and notations}

The parameters of the car-following model used are:

- $n$, examined vehicle (user);

- $h_{n, a}(t)$, spatial headway at time $\mathrm{t}$ between vehicle $\mathrm{n}$ and leader vehicler $\mathrm{n}-1$ travelling on the same lane of link a;

- $v_{n, a}(t)$, speed of vehicle $\mathrm{n}$ at time $\mathrm{t}$ on link a.

The car-following model is calibrated for each link a (or classes of links) of the network defining exogenously the following four macroscopic parameters:

- $\mathrm{v}_{0, \mathrm{a}}$, free speed;

- $\mathrm{v}_{\mathrm{cr}, \mathrm{a}}$, speed at capacity; 
- $\mathrm{C}_{\mathrm{a}}$, capacity;

- $\mathrm{K}_{\mathrm{j}, \mathrm{a}}$, jam density.

The parameters of the gap-acceptance model at not-signalized nodes are the following:

- $\mathrm{t}^{\prime}$, arrival time of vehicle at the node;

- $\mathrm{T}_{\mathrm{n}}$, maximum waiting time for the vehicle $\mathrm{n}$ starting from $\mathrm{t}$, after which the vehicle starts the manoeuvre;

- $\mathrm{G}_{\mathrm{n},}{ }^{\mathrm{cr}_{1}}$, critical gap for vehicle $\mathrm{n}$ at time $\mathrm{t}$ ';

- $G_{n}{ }_{n}{ }^{c r}(t)$, critical gap for vehicle $\mathrm{n}$ at time $\mathrm{t}$, between $\mathrm{t}^{\prime}$ and $\mathrm{T}_{\mathrm{n}}$;

- $\mathrm{G}_{\mathrm{n}}{ }^{\mathrm{b}}$, value of critical gap if the vehicle executes a straight through manoeuvre and if the conflicting link, with higher prority, has a single lane;

- $\mathrm{m}$, type of vehicle manoeuvre at the node (straight through, left turn, right turn);

- $\mathrm{nl}$, number of opposing lanes for the vehicle to cross;

- $\Delta G_{n}(m, n l)$, increment of critical gap for vehicle $\mathrm{n}$ due to more articulated manoeuvre than straight through one (left turn, right turn) and when $n l>1$.

\subsection{Used model}

The traffic flow models used are proposed in [13] and [26].

The link model combines a car-following model and a lane-changing model able to simulate manoeuvres in discretionary and mandatory conditions.

The car-following model is a relationship between spatial headway $h_{n, a}(t)$ and speed $v_{n, a}(t)$ for each link a, whose equation is:

$$
h_{n, a}(t)=\alpha_{1, \mathrm{a}}+\left[\alpha_{2, \mathrm{a}} /\left(\mathrm{v}_{0, \mathrm{a}}-v_{n, a}(t)\right)\right]+\alpha_{3, \mathrm{a}} v_{n, a}(t)
$$

where

$$
\begin{aligned}
& \alpha_{2, \mathrm{a}}=\left(1 / \mathrm{k}_{\mathrm{j}, \mathrm{a}}\right)\left[1 /\left(\beta_{\mathrm{a}}+1 / \mathrm{v}_{0, \mathrm{a}}\right)\right] \\
& \alpha_{1, \mathrm{a}}=\beta_{\mathrm{a}} \alpha_{2, \mathrm{a}} \\
& \alpha_{3, \mathrm{a}}=\left[-\alpha_{1, \mathrm{a}}+\mathrm{v}_{0, \mathrm{a}} / \mathrm{C}_{\mathrm{a}}-\left(\alpha_{2, \mathrm{a}} /\left(\mathrm{v}_{0, \mathrm{a}}-\mathrm{v}_{\mathrm{cr}, \mathrm{a}}\right)\right)\right] / \mathrm{v}_{\mathrm{cr}, \mathrm{a}} \\
& \beta_{\mathrm{a}}=\left(2 \mathrm{v}_{\mathrm{cr}, \mathrm{a}}-\mathrm{v}_{0, \mathrm{a}}\right) /\left(\mathrm{v}_{0, \mathrm{a}}-\mathrm{v}_{\mathrm{cr}, \mathrm{a}}\right)^{2}
\end{aligned}
$$

with $\alpha_{1, a}, \alpha_{2, \mathrm{a}}$ e $\alpha_{3, \mathrm{a}}$ parameters to be calibrated for each link a, defining exougenously $\mathrm{v}_{0, \mathrm{a}}, \mathrm{v}_{\mathrm{cr}, \mathrm{a}}, \mathrm{C}_{\mathrm{a}}, \mathrm{k}_{\mathrm{j}, \mathrm{a}}$.

The lane-changing model is based on decisional rules and allows to simulate discretionary and mandatory manoeuvres. The latter depend on traffic conditions on the link, the former on the network geometry.

According to the model, a driver $\mathrm{n}$ evaluates the possibility to execute a discretionary lane-change if his desidered speed is greater than the speed of the leader vehicle $\mathrm{n}-1$. The lane-change is executed after the evaluation and comparison of different potential speeds. The first speed is the one at which the 


\section{Environmental Health Risk}

driver can travel along the current lane, the others are the speeds at which the driver can travel if he moves on adiacent lanes. The driver will reach the lane that allows him to travel at the highest speed among the potential ones. The lanechange, however, is conditioned from the availability of a sufficient gap on the destination lane.

The driver executes a mandatory lane-change if he is forced from the link geometry. The lane-changing manoeuvre is actuated gradually through the definition of a softwall and a hardwall. The softwall is a road section, from which the driver perceives the necessity to change lane, while the hardwall is a downstream road section, that can not be passed from the driver, because this would make impossible the lane-change execution and the achievement of the destination lane. When the driver is between the softwall and the hardwall, he is progressively forced to execute the manoeuvre.

The gap-acceptance model [31], based on the definition of critical gap for vehicle $\mathrm{n}$ at time $\mathrm{t}$ between $\mathrm{t}^{\prime}$ and $\mathrm{T}_{\mathrm{n}}$, is deterministic and has the following equation:

$$
G_{n}^{c r}(t)=\mathrm{G}_{\mathrm{n}}{ }^{\mathrm{cr}}-G_{n}{ }^{c r},\left(t-t^{\prime}\right) /\left(\mathrm{T}_{\mathrm{n}}-\mathrm{t}^{\prime}\right) \quad\left(\mathrm{t}^{\prime} \leq \mathrm{t} \leq \mathrm{T}_{\mathrm{n}}\right)
$$

where

$$
\mathrm{G}_{\mathrm{n}}{ }^{\mathrm{cr} \mathrm{r}^{\prime}=} G_{n}^{c r^{\prime}}(m, n l)=\mathrm{G}_{\mathrm{n}}^{\mathrm{b}}+\Delta G_{n}(m, n l)
$$

According to (7), the value of $\mathrm{G}_{\mathrm{n}}{ }^{\mathrm{cr}}$ increases when the manoeuvre at the node is more articulated than the straight through one and the number of lanes of the conflicting link increases $(\mathrm{nl}>1)$. The value of $G_{n}^{c r}(t)$ linearly decreases from time $t^{\prime}$ until it goes to zero at time $T_{n}$, according to (6), in case the densities on the conflicting link are high and cause delay for vehicle in the execution of the desidered manoeuvre.

The path choice model operates on a variable path choice set and it is pre-trip and deterministic.

\section{Procedures}

The simulation of the evacuation from an urban area is carried out with the support of a microscopic software, called Integration [26].

It contains an algorithm where the car-following model (1) and the lanechanging model are combined toghether to represent the vehicular flow on links with multiple lanes, and the gap-acceptance model is able to manage conflicting vehicular flows at not-signalized nodes.

The algorithm operates according to the following steps:

- vehicles generation at the origins; if sufficient capacity exists on entering links vehicles enters into the network, otherwise vehicles wait to enter in virtual queues;

- each generated vehicle selects the path with the minimum travel time from the origin to the destination according to the current traffic conditions on the 
network (pre-trip choice);

- the space-time traiectory of each vehicle from the origin to the destination comes out from the interaction with other vehicles on the links and at the nodes.

The vehicle advancing procedure on the links combines the car-following model

(1) with the lane-changing model, according to the following scheme:

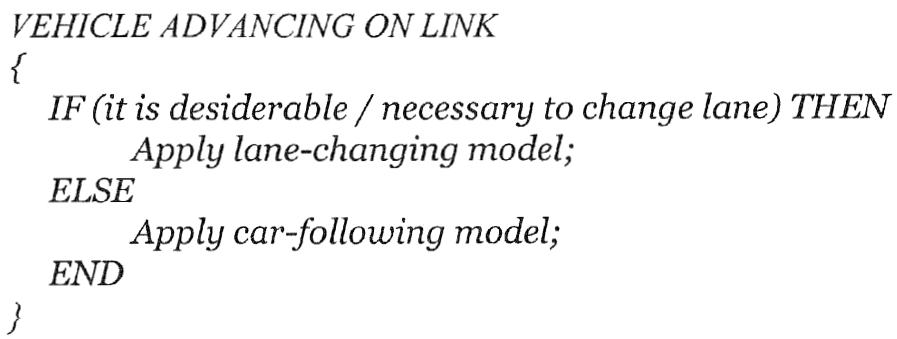

The gap-acceptance procedure at not-signalized nodes requires the specification of the conflicting links of the current one, with higher priority.

If it is not exougenously specified, the value of critical gap for the vehicle $n$, $G_{n}{ }^{c r}(t)$, is obtained from the following procedure:

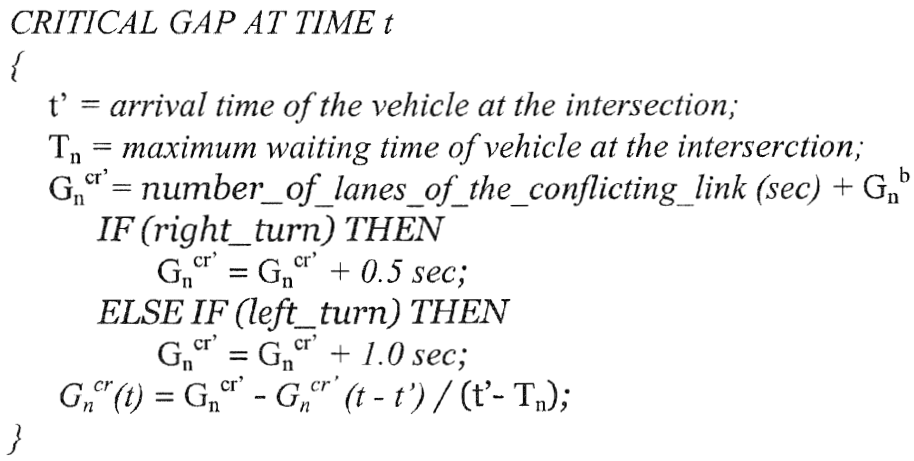

\section{Conclusions and future work}

The analysis and management of a road transportation system in emergency conditions is necessary for planning the evacuation of a popolated area due to the approximation of a calamitous event. In such context, in which temporary sovrasaturation phenomena of some transportation supply elements, queues formation and dissipation are present, methods and procedures for Dynamic Traffic Assignment (DTA) become necessary, which can have different models or specifications: pseudo dynamic, mesoscopic, microscopic.

In the paper microsimulation models and procedures for the analysis and management of a road transportation system in emergency conditions are presented. An application to a small town (Zafferana Etnea, Italy) is described in [43], where the road trasportation system is simulated for different configurations 


\section{Environmental Health Risk}

of supply (different number and location of assembly centers) and demand (different distributions among the assembly centers), according to a "what if" approach.

The microscopic approach allows a disaggregate analysis of each driver behaviour in terms of speed and acceleration and the simulation of queuing and lane-changing phenomena; but it needs high computation times for extended transportation networks analysis and large amount of data for the behavioural rules definition. So, it is suitable for detailed off-line analyses of evacuation phases from not extended areas (industrial areas, small/medium urban areas, ....), supporting transportation planning activities in emergency conditions. Moreover, it can support the calibration of link and node models, used in static and mesoscopic approaches, due to the high detailed representation of traffic phenomena. But, it is not suitable for real time analyses and for extended transportation networks analyses (large cities, metropolitan and sub regional areas, ..)

Future work concerns the the project of the departure time management at the origins and the application to microsimulation procedures to a more extended urban areas.

\section{References}

[1] Velonà, P. \& Vitetta, A. Evolution of an urban transportation system in emergency conditions: analysis through a pseudo-dynamic assignment model. In this book. 2003.

[2] Di Gangi, M. \& Velonà, P. Use of a mesoscopic dynamic assignment model for approaching the evolution of an urban transportation system in emergency conditions. In this book. 2003.

[3] Chandler, R., Herman \& R., Montroll, E., Traffic dynamics: studies in carfollowing. Operations Research 6, 165-178, 1958.

[4] Gazis, D., Herman, R. \& Potts, B., Car-following theory of steady-state traffic flow. Operations Research 9, 449+, 1959.

[5] Gazis, D., Herman R. \& Rothery R., Nonlinear follow-the-leader models of traffic flow. Operations Research 9, 545+, 1961.

[6] Herman, R., Montroll, E.W., Potts, R.B. \& Rothery, R. Traffic dynamics: analysis of stability in car following. Operations Research, 7, 86-106, 1959.

[7] Edie, L., Car-following and steady-state theory for uncongested traffic. Operations Research 9, 66+, 1960.

[8] May, A. \& Keller, H., Non-integer car-following models. Highway Research Record 199, 32-43, 1967.

[9] Ceder, A. \& May, A.D., Further evaluation of single and two regime traffic flow models. Transportation Research Record 567, 1-30, 1976.

[10] Ceder, A., The accuracy of traffic flow models: a review and preliminary investigation. Traffic Engineering and Control. December, 541-544, 1978.

[11] Ozaki, H., Reaction and anticipation in the car following behaviour. Proceedings of the $13^{\text {th }}$ International Symposium on Traffic and Transportation Theory, 349-366, 1993. 
[12] Subramanian, H., Estimation of car-following models. Master's thesis. MIT. Department of Civil and Environmental Engineering. Cambrige. Massachussets, 1996.

[13] Van Aerde, M., A Single regime Speed-Flow-Density Relationship for Congested and uncongested Highways. $78^{\text {th }}$ Annual Meeting Transportation Research Board. Washington D.C. USA, 1997.

[14] Yang, Q., A simulation laboratory for evaluation of dynamic traffic management systems. P.h.D. Thesis. MIT. Department of Civil and Environmental Engineering. Cambrige. Massachussets, 1997.

[15]Zhang, Y., Owen L.E. \& Clark J.E., A multiregime approach for microscopic traffic simulation. $78^{\text {th }}$ Annual Meeting Transportation Research Board. Washington D.C. USA, 1999.

[16] Gipps, R.B., A behavioural car-following model for computer simulation. Transportation Research Board., Vol 15-B, No.5, 105-111, 1981.

[17] Gipps, R.B., A model for the structure of the lane-changing. Transportation Research Board. Vol 20-B, No.5, 403-414, 1986.

[18]Ahmed, K. I., Ben-Akiva M. E., Koutsopoulos H. N. \& Mishalani R. G., Models of Freeway Lane Changing and Gap Acceptance Behaviour. Proceeding of ISTTT. Lyon, 1996.

[19] Koutsopoulos, H.N. \& Yang, Q., A microscopic traffic simulator for evaluation of dynamic traffic management systems. Transportation Research C. Vol.4, N.3. 113-129, 1996.

[20] Federal HighWay Administration, Highway Capacity Manual. TRB Special report 209. Washington D.C. Office of Research. FHWA, 1994.

[21] Hidas, P. \& Behbahanizadeh, K., Microscopic simulation of lane Changing Under Incident Conditions. $14^{\text {th }}$ International Symposium on Transportation and Traffic Theory. Jerusalem, 1999.

[22] Astarita, V., Florian, M. \& Musolino, G., A microscopic traffic simulation model for the evaluation of toll station systems. Proceedings of the 2001 IEEE Intelligent Transportation Systems, Oakland (USA), 692 -697, 2001.

[23] Festa, D.C., Gattuso, D. \& Vitetta, A., Un modello comportamentale per il cambio corsia in ambito autostradale. VI Convegno SIDT. Bologna, 1997.

[24] Cantarella, G.E. \& Festa, D.C. (eds), Modelli e Metodi per l'Ingegneria del Traffico. Collana Trasporti. Ed. FrancoAngeli, 1998.

[25] Transportation Simulation Systems, AIMSUN2 - Version 4.0. User's Manual. Barcellona, Spagna, 1999.

[26] Van Aerde, M. \& Transportation Research Group, INTEGRATION-Release 2.30. User's Guide. Volume I, II, III. M. Van Aerde \& Assoc., Ltd, 2000.

[27] Herman, R. \& Weiss, G.H., Comments on the highway crossing problems. Operations Research 9, 828-840, 1961.

[28] Drew, D.R., LaMotte, L.R., Buhr, J.H. \& Wattleworth J.A., Gap acceptance in the freeway merging process. Texas Transportation Institute 430-2, 1967.

[29] Daganzo, C.F., Estimation of gap acceptance parameters within and across the population from direct roadside observation. Transportation Research Part B 15B, 1-15, 1981.

[30] Mahmassani, H. \& Sheffi, Y., Using gap sequences to estimate gap acceptance functions. Transportation Research, Part B 15B, 143-148, 1981. 
246 Environmental Health Risk

[31] Van Aerde, M. \& Velan, S., Relative effects of opposing flow and gap acceptance on approach capacity at uncontrolled intersections. $75^{\text {th }}$ Annual Meeting of the Transportation Research Board, Washington D.C, 1996.

[32] Cascetta, E., Transportation systems engineering: theory and methods, Kluwer, 2001.

[33] Cascetta, E. \& Cantarella, G.E., Day-to-day and within-day dynamic stochastic assignment model. Transportation Research. 25A, 277-291, 1991.

[34] Cascetta, E. \& Cantarella, G.E., Modeling dynamics in transportation networks: State of the art and future developments. Simulation practice and theory 1.65-91, 1993.

[35] Mizar Automazione, NEMIS: NEtwork MicroSimulation Package. User Manual, 1991.

[36] Fellendorf, M. \& Vortish, P., Integrated modeling of transport demand, route choice, traffic flow and traffic emissions. 79th Annual Meeting of the TRB. Washington. USA, 2000.

[37] Marzia, S. \& Sala, G., Evoluzione del microsimulatore SPEACS verso la simulazione di une rete autostradale. Atti del convegno CNR/PFT2: "Supervisione e controllo del traffico autostradale". Roma, 1998.

[38] Adamo, V., Astarita, V. \& Polidoro R., La simulazione dinamica dei flussi pedonali: metodologie ed applicazioni per il calcolo dei transitori nello svuotamento delle aree e strutture affollate. ISCS Conference. Roma, 1996.

[39] Di Gangi, M., Luongo, A. \& Polidoro R., Una procedura di carico dinamico per la valutazione dei piani di evacuazione. In Metodi e Tecnologie dell'Ingegneria dei Trasporti. Seminario 1999, a cura di G.E. Cantarella e F. Russo, FrancoAngeli, 2001.

[40] Velonà, P. \& Vitetta, A., Procedure di assegnazione pseudo dinamica per la valutazione del tempo di evacuazione di una rete di trasporto. Atti del Convegno INPUT 2001. Isole Tremiti, 2001.

[41] Russo, F. \& Vitetta, A., Urban road transportation analysis in emergency conditions: models and algorithms. Proceedings of Urban Transport 2000, Wessex Institute of Technology. Sucharov e Brebbia ed., WIT Press Boston, 533-542, 2000.

[42] Russo, F \& Vitetta, A., Urban transportation system analysis in emergency conditions. In this book. 2003.

[43] Di Gangi, M., Musolino, G., Russo, F., Velonà, P. \& Vitetta A. Analysis and comparison of several urban road transportation assignment models. In this book. 2003. 